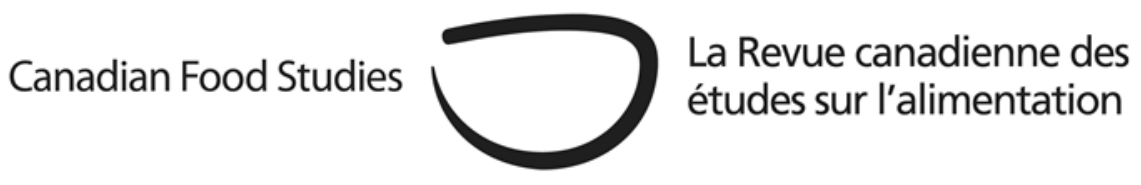

Interview

\title{
Wayne Roberts: Food Systems Thinker, Public Intellectual, "Actionist"
}

\author{
Patricia Ballamingie ${ }^{a^{*}}$ and Charles Z. Levkoe ${ }^{b}$ \\ ${ }^{a}$ Carleton University \\ ${ }^{\mathrm{b}}$ Lakehead University
}

\section{Abstract}

Wayne Roberts (1944-2021) was a food systems thinker, public intellectual, and "actionist." This text was developed from a series of oral history interviews conducted between December 2020 and January 2021. It touches upon several of the key themes addressed during the interviews: adopting a food systems approach; employing the power of ideas; identifying solutions and being propositional; acknowledging progress for political credit; enhancing impact through media, old and new; working strategically to "seed" then "tip"; influencing government; and forming alliances with academics and other champions. In addition, we provide links to additional resources. In this article, which inaugurates the Interviews section of Canadian Food Studies/La Revue canadienne des études sur l'alimentation, we aim to do justice to the gift of Wayne's experiences and knowledge by sharing a selection and synthesis of his words.

Keywords: Food policy; food policy councils; food systems 
Introduction

Wayne Roberts was a food systems thinker, public intellectual, and "actionist." He held a PhD in social and economic history from the University of Toronto and spent his life working for social and environmental justice in the areas of food systems, community organizing, education, media, and union administration. While perhaps best known for his leadership of the Toronto Food

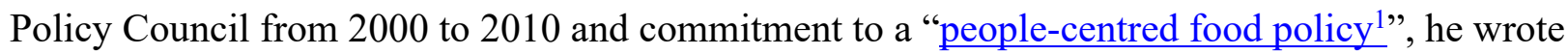
prolifically throughout his life. His writings can be found in multiple scholarly journals, popular magazines (including a regular column in NOW Magazine), regular blog series (including Medium $^{2}$, Rabble.ca ${ }^{3}$, and Resilience ${ }^{4}$ ), and 12 books he wrote and co-authored. Between 1977 and 1982, Wayne worked as an assistant professor in the departments of History and Labour Studies at McMaster University, and from 2010 to 2015, he served as a visiting scholar at the University of Toronto's New College. He taught food systems courses at York University and the University of Toronto and gave lectures around the world. In considering and discussing political strategies and tactics, Wayne consistently referenced critical theorists and non-academic authors, demonstrating his breadth and depth of knowledge. He played a foundational role in food movements across the globe and contributed to key organizations such as the Community Food Security Coalition, Food Secure Canada, and the Canadian Association for Food Studies (CAFS), participating actively in governance and annual conferences. Wayne received the Queen's Diamond Jubilee Medal in 2013 and the CAFS Lifetime Achievement Award ${ }^{5}$ for 2019-20. In January 2021, after a short battle with leukemia, Wayne died at the age of $76^{6}$. During his Celebration of Life ${ }^{7}$ on February 21, 2021, he was described as not only principled, brilliant, strategic, irreverent, prolific, and connected, but also loving, joyous, funny, generous, gracious, inclusive, playful, and loyal.

\footnotetext{
${ }^{1}$ https://www.resilience.org/stories/2019-01-25/connected-critics-branding-for-a-people-centered-food-system/

2 https://medium.com/@wayneroberts

3 https://rabble.ca/author/wayne-roberts/

4 https://www.resilience.org/stories/content-partner/wayne-roberts-blog-2/

5 https://foodstudies.info/news-conferences/cafs-awards/

${ }_{6}$ Tributes to Wayne Roberts were published in Corporate Knights (https://www.corporateknights.com/foodbeverage/remembering-food-policy-writer-wayne-roberts-a-radical-happyist/), Now Magazine (https://nowtoronto.com/news/in-memoriam-wayne-roberts-1944-2021), The Toronto Star (https://www.thestar.com/life/together/remembrance/2021/04/18/the-joy-seeker.html), and CBC (https://www.cbc.ca/news/canada/toronto/wayne-roberts-remembered-1.5884879).

${ }^{7}$ https://www.facebook.com/Dr.WayneRoberts
} 
It seems the core themes of Wayne's life were love, solidarity, gratitude, joy, and an unwavering pursuit of justice and the common good.

"I can't give Wayne a fitting obituary that adequately covers his many contributions to food systems work in Canada and the U.S., but I'm sure that many people can tell stories of how he touched their lives. Wayne was always bubbling over with good spirits and ready to see silver linings in the darkest clouds. I will miss him very much-it's hard to believe we won't hear his laugh and pithy analyses again."

-Molly D. Anderson, William R. Kenan Jr. Professor of Food Studies, Middlebury College

Between December 14, 2020 and January 10, 2021, we had the privilege of conducting a series of oral history interviews with Wayne as part of a broader research project focusing on Participatory Food Systems Governance (PFG). The PFG project aims to explore effective, innovative, and collaborative approaches to food governance for building healthy, equitable, and sustainable food systems. Moreover, it aims to develop a deeper understanding of the possible trade-offs, limitations, and paradoxes associated with civil society organizations' active participation in multi-stakeholder and collaborative governance arrangements.

We interviewed Wayne by phone and using the Zoom platform in five installments, for a total of about ten hours. His beloved partner, Lori Stahlbrand, was at his side for each session. Our conversations focused on food governance, but also flowed naturally into memory and connection, skipping a pebble across myriad themes. Wayne proved his usual lucid, cogent, and funny self throughout. We bore witness to the grace with which Wayne lived joyously in the moment - an approach he (and good friend, Jim Harris) dubbed being a "radical happyist" (Harris, 2021). Through this text, we aim to do justice to the gift of his time and knowledge by sharing a selection and synthesis of his words.

The discussions were conducted as a semi-structured interview and followed a core set of questions sent to Wayne in advance. We analyzed the five transcripts to identify the key themes that are covered below. Where relevant, links to additional resources are included, provided by Wayne himself. We have also embedded a representative sampling of the outpouring of tributes from around the globe that Wayne's passing prompted. The audio (and selected video) recordings from our conversations will be archived on a publicly accessible server, so that future scholars and practitioners might have access to this material. 


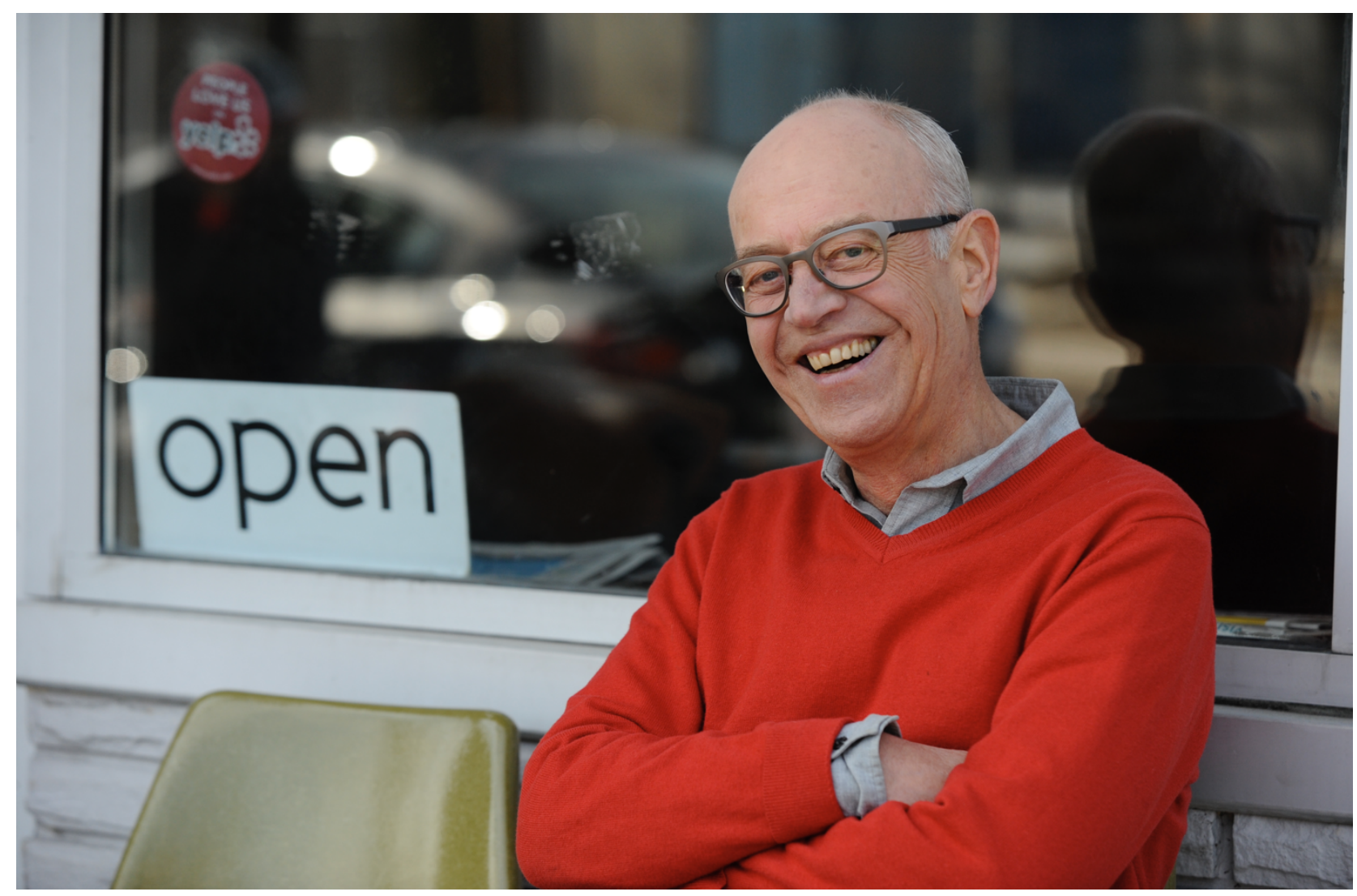

Photo credit: Michelle Quance

Wayne Roberts's Theory of Change

Throughout our interviews, Wayne reflected on key tactics he had employed to effect change within and around food systems - most of which were informed by his long history in the labour movement (see Roberts, 1994; 2014a; 2014b; Roberts \& Brandum, 1995; Roberts \& Ehring, 1993; Roberts et al., 1999). We characterize what follows as Wayne's Theory of Change but wish to flag that Wayne did not frame these contributions as such, and they should be understood as necessarily partial and incomplete.

\section{Adopt a food systems approach}

Throughout Wayne's life and career, he proved committed to the idea of applying systems thinking in relation to food. 
In some of his earliest writings (see Roberts, 2014a; Roberts \& Brandum, 1995) he was a proponent of the idea of food systems thinking - the idea that the various interactions within the food web, along with social and ecological relationships, cannot be understood in isolation. Wayne described food as part of an interconnected and interdependent system that is "hidden in plain sight" (Roberts, 2014a, p. 11). He wrote: "The world of food is poised on the edge of problems and opportunities. Welcome to a subject that impacts upon everyone and invites everyone to make a difference" (Roberts, 2014a, p. 11). Failing to recognize and engage food as part of a system can lead to even greater challenges, sometimes described as "wicked problems" (Pohl et al., 2017). Wayne committed himself to advancing a food systems approach through his research, teaching, and writing, even if it was messy and complex. He suggested, "We need not be bound by neat systems thinking, just systems thinking."

Wayne pointed to multiple instances of isolated food-related thinking he considered to be extremely problematic. For example, he discussed the binary that many academics and activists have (perhaps inadvertently) created between poverty and food. Acknowledging poverty as a major concern - directly connected to issues of equity and justice - he suggested that solutions were much more complex than often perceived. In other words, addressing poverty is not a silver bullet that solves all food systems issues. Instead of positioning specific ideas and approaches in opposition to one another, Wayne suggested that a spectrum of options was needed: "Stage one, the lowest level, would be offering calories to help someone keep body and soul together without any concept of meal, any sense of togetherness. [There's] no dignity, no nutrition, no culture of food." Further stages would include healthy, culturally appropriate food as a core part of labour, housing, transportation, and other aspects of livelihoods and well-being.

In another example, Wayne mused on the problematic binary typically used to critique food banks: "It's virtually impossible to be less efficient than food banks!" While he opposed them in favour of a stronger social safety net, he also acknowledged that it is an instinct for people to want to help others in their community. He suggested that the problem is when antipoverty organizations fail to support people that have been made vulnerable by using food banks as an opportunity to actualize issues of equity and social justice. Wayne argued, "We don't need a binary ... We need to raise the level of what a food bank does for its clients, including empowerment, English-language training, and access to job programs." In other words, food problems cannot be solved by money alone, either by giving people free food or by giving them higher incomes. Food is also about reducing social isolation, generating environmental benefits, creating stronger communities, and much more: "You have to look at the whole systemproblems of nutrition are not just problems of nutrition, they are problems of the food system. 
And problems of hunger are not just problems of hunger, they are problems of the food system and the way that we have constructed the food system."

"If there were a Hall of Urban Food Systems Fame, Wayne Roberts would be among the first to [be inducted] from North America who contributed so much to the integration of food in health policy, food in urban planning and food in democratic governance! His humour, his wisdom and his wonderful speaking and writing on his passion for 'food solutionaries' were guideposts for so many of us who follow in this giant's food steps!"

—Thomas Forster, New School Food Studies

Wayne argued, when understood through a food systems lens, food could be used as a valuable tool to solve multiple problems in cities (see Roberts, 2001; 2014b). He joked, "The way to a city's heart is through its stomach." This notion informed Wayne's faith in and commitment to food policy councils, and that food-centred partnerships between civil society and municipal governments could serve as a lever for cities to act on issues like green roofs, transportation, housing, zoning, and environmental challenges. Wayne viewed food policy councils as an integral part of food movements because they embrace a food systems approach (see Koç et al., 2008; Roberts, 2014b, 2016). Wayne was a primary author of Toronto's Food Charter, which was unanimously adopted by Toronto City Council in 2001 and was a guiding document for the Toronto Food Policy Council. The charter formally brought together the then largely disparate issues of poverty, hunger, sustainable agriculture, health, and others: "It was about improving the city by improving food."

"Wayne was best known as coordinator of the Toronto Food Policy Council for a decade in the 2000 s, but he was beyond that a pillar in the emergence of recognizing cities and their regions as central actors in food systems, and one of the most influential thinkers and disseminators of thinking about the place of food in cities. He always combined astute thoughts with joyful laughs, sharp zingers and perfectly constructed writing."

- Joe Nasr, Centre for Studies in Food Security, Ryerson University

\section{Employ the power of ideas}

In addition to embracing a food systems approach, Wayne understood implicitly how knowledge, power, and discourse are intertwined. 
He advocated, "We must define ourselves in terms of the power of ideas," noting his own unique positionality: "I might be the weakest in terms of resources, but I am the guy with the idea!"; "Think of the power you bring to something, rather than the power you don't have." He mused that most civil servants have a relative paucity of ideas, enthusiasm, and imagination, and that those of us seeking to effect positive change can use ideas "as a battering ram to move ahead in the world." For example, in relation to his dedication to expanding community gardens and farms in the City of Toronto, he asserted that "the limit on urban agriculture is the limit of our own imagination." Wayne would have us dream big and imagine alternative food futures, prefiguring them first in our minds and then in the material world.

Related to the power of ideas, Wayne reflected on a key historical discursive shift: the reframing of the significance of food beyond it being "a women's issue." He explained that some of the early work of the Toronto Food Policy Council involved broadening media coverage of food beyond the "women's section of a magazine." To this end, he felt the Toronto Food Policy Council (and food movements more broadly) had made some significant success: "By 2004, food was in Business, Lifestyle, Restaurants, etc.... We broke out of the hammer grip of where food would be covered" (see Roberts, 2009). Of course, food is increasingly understood as a portal through which to achieve a myriad of environmental, health equity, and social justice ends - a conceptualization built upon these earlier discursive shifts.

\section{Identify solutions, be propositional}

According to Wayne, the food movement has historically identified problems, but had the opportunity to effect change more potently by identifying solutions. He contended, "You need to always be propositional, rather than oppositional." Wayne viewed this approach as a necessary maturing of the movement. He also saw tremendous opportunity in the media's appetite to cover food movements - largely because food work can be so positive (for example, community gardens, healthy school lunch programs, community kitchens, edible landscaping, etc.) Moreover, campaigns that move toward something beautiful are good ways to engage people. And he stressed, there is "no one focus or way of coming at it."

Wayne offered very practical advice: "We must address the problems people [actually] have, not the problems we imagine them to have." He also thought in terms of specific tactics: "We must list all the problems [and then ask] who has the same problems? For whom do we have a solution?" He further prodded, "What is a big problem that the government has that has a long list of beneficiaries and low resistance to change?"

However, he felt that for food movement actors to identify solutions, they must agree upon and aim for discrete wins. In this vein, Wayne alluded to strategies from the labour movement. He explained: "Unions are successful organizations because members begin asking for the moon, but then negotiators narrow [these demands] to three or four issues." 
He further advised that rather than "going for the whole ball of wax," activists should stay closely focused on goals that meet several criteria. Wayne argued for identification of a "low complexity" goal for which there is "low resistance to adoption" and a "good list of immediate beneficiaries from doing it right." These beneficiaries are potential allies in the fight. To make a goal a reality, it needs both "an internal, civil service champion, and an external champion."

Wayne offered the inability of local producers to meet the increasing demand for local food as a tractable problem. For example, local productive capacity can be bolstered, and value-added processing can be strengthened. This was a way to avoid creating wicked problems with competing and contradictory underpinnings. Wayne argued that determining what to tackle requires an understanding of food systems, identification of both wicked and tractable problems, self-discipline, and, ultimately, political judgement.

\section{Acknowledge progress for political credit}

Without doubt, Wayne's history representing workers infused his food scholarship and activism. He lauded the tactics of Bob White, the founding president of the Canadian Auto Workers (now Unifor) from 1984 to 1992, and president of the Canadian Labour Congress from 1992 to 1999. Wayne explained, "Take, for instance, the most militant trade unionist... No one did a contract with Bob White without a highly public letter of thanks!" He further asserted, "Autoworkers always give applause. They have people who know how it works, and we [proponents within food movements] don't." In this sense, Wayne adopted a deeply pragmatic and strategic approach to bringing about change. He argued that activists must be willing to compromise: "You [government, industry] do this, it will help solve this, and we will shut up about the other issue." In other words, Wayne argued the food movement must acknowledge progress, even partial progress, for political credit, just as the labour movement has done successfully in the past, to secure gains in the future.

\section{Enhance impact through media, old and new}

Early in his career, Wayne recognized "media as an incredible zone of power," - using it strategically to shift the discursive framing of key issues, build reputation, and ultimately, enhance impact. He waxed, "We [food movement actors] have one of the most popular, mediacovered movements of the past twenty years. And coverage is almost always positive." He saw potential for media campaigns to influence the government but stressed the need to "be in the news a couple times a week" to affect power.

Wayne also lamented the disappearance of the beat system in news media, in which reporters specialize in a particular topic, sector, or organization. 
Realizing that former beat reporters might struggle to navigate a broader story terrain, he put the word out that if someone didn't know where to go for a story, they should go to him, and he would direct them. Wayne gained the trust of the media by using his knowledge of the labor system to compensate for their lack of knowledge as beat reporters. When Wayne started at the Toronto Food Policy Council, he put the same word out regarding food stories. He demonstrated his prowess for media literacy in the multiple blog posts and articles he published on a wide range of topics (food, labour, democracy, geopolitics, public policy, economics), targeting audiences from food systems scholars and activists to policy makers and the public.

Wayne also proved more than capable of adapting to changes in media usage. Notably, he maintained an active presence on many social media platforms, viewing online communities as “an excellent place to develop reputation." His Twitter account ${ }^{8}$ boasted almost 100,000 followers, and in the last year of his life Wayne continued to foreground relevant hashtags: "During \#coronavirus, I post on \#healthequity, \#foodjustice, \#urbanagriculture \#greeninfrastructure." Wayne's website- "where local sustainable food policy meets action"along with his Wikipedia ${ }^{9}$ entry and Facebook page ${ }^{10}$ served as another hub for his work, providing details of his background, publications, and more than 500 speaking engagements (including in Mexico, England, Ireland, India, and South Korea). His use of old and new media aimed to augment the impact of his other efforts, while maintaining and growing his visibility. As Wayne put it, "[an activist's] number one asset is reputation... That's what makes us able to scale up and down."

\section{Work strategically to "seed" then "tip"}

Wayne spoke about the power of "seeding" as a big theme in his life. He seeded people by supporting their work and augmenting their roles, notably Ellen Desjardins and Alison BlayPalmer, both of whom went on to play national and international roles in food systems work. He seeded strategic alliances, encouraging activists to "find another group which has the resources to do what you cannot." As his partner, Lori Stahlbrand, noted, the metaphor also extends to the ways Wayne planted story ideas. "Wayne would offer insights into not only the stories journalists were calling about, but also the ones Wayne was interested in seeding."

\footnotetext{
${ }^{8}$ https://twitter.com/wrobertsfood

9 https://en.wikipedia.org/wiki/Wayne_Roberts_(activist)

${ }^{10} \mathrm{https://www.facebook.com/WayneRobertsPage}$
} 


\begin{abstract}
"Wayne's vision and example made everyone he touched understand the power of good food. He helped us see its regenerative potential to make the world more socially just, green, healthy and vibrant." -Alison Blay-Palmer, UNESCO Chair on Food, Biodiversity and Sustainability Studies, Director, Centre for Sustainable Food Systems, and Professor, Wilfrid Laurier University
\end{abstract}

Once enough seeds had been sown, Wayne identified the possibility of "tipping" the system towards progressive change - crediting Malcolm Gladwell (2000) for this notion. He reflected, "I don't have any money, expertise, connections, budget. But if you are ready to tip, I can help you tip." While Wayne in fact possessed expertise and connections in spades, he also clarified: "You can tip an issue, but you cannot create an issue where none exists."

Wayne suggested, "We have to find an issue that isn't wicked. [For example,] buying local food from local farmers only has winners." He argued that there needs to be greater collaboration and agreement of key issues to push collectively, but that the law of politics constrains progress to one issue at a time, and: "Thus, we must go in with the tippers." He quipped, "there used to be a saying in management theory: two objectives is no objective." And he further asserted: "If the Left is pushing one issue, it's got to shut up on the other. Because you're only getting one issue. That's just the law of politics. So, we're all going in with 18 issues, but we really should only be going in with the tippers."

\title{
Play ball to influence government
}

Wayne offered several insights on working the system at different scales to influence government and to get beyond what he described as "a culture of no." To begin, he noted the very real constraints of influencing governmental policy around wicked problems such as hunger and poverty. "Government won't touch the food security thing because there are too many guarantees of failure... Whichever way you turn, it's not going to be adequate." He explained the social and psychological underpinnings of why the government won't act: "If it doesn't turn out, [food movement actors] will condemn you, and that doesn't encourage risk taking." He identified this approach as a potential area for improvement, noting that "food movement people aren't really engaged politically" and "[the] food movement has made huge progress in many areas, but not in policy." Wayne wanted to see the food movement "mature" to work cooperatively with the government to put solutions in place, since "permanent and transformative change demands institutional- and political-level work."

Wayne stressed the need to approach the right level of government with the right problem. As he explained, "In Canada, the provinces deal with issues of food and health and education." If efforts occur mainly at the national level, we are therefore "knocking on the wrong door," since "the feds cannot move on it, and if they can, it is limited action." 
He specified that when asking the federal government for change, it must be proportionate to what they can deliver. Otherwise, he said, "federal governments are where good ideas go to die... We really lack the constituency for national issues." Wayne went on to note the efficacy of Joanne Bays' work as National Director of Farm to Cafeteria Canada (F2CC), explaining that "she picked areas where governments were looking for something, like in New Brunswick and northern BC... In politics, if you want to do food, you have to do provinces."

Wayne revealed his tactical nature in explaining what happens once you have decided on the issue you wish to influence and have developed the appropriate level of public engagement: "To have an impact, you need to cause a problem for someone in the system... You need to ensure consistent pain for politicians for not solving the problem." He suggested that even in the current pandemic, with so much attention on the poor quality of care in privatized nursing homes, "you [would still] need a four-year commitment of hounding them." Yet Wayne also advocated for building relationships with government officials, and not simply being a pain in their necks. He explained, "The food movement has missed that step, because we saw policy as the crux of the matter, and not relationship building. But out of relationships come the policies that solve the problems."

"Wayne was indeed a pollinator of ideas. He played a cardinal role in influencing the massive work we have done in East, Central and Southern Africa on food systems and urban sustainability. We will miss his deep reflections and critical perspectives on policy interventions and IRO food security in African cities."

- Mulala Danny Simatele, Professor, Global Change Institute, University of the Witwatersrand, Johannesburg, South Africa

"Wayne was a true legend in the urban food world. So many of us and so many of the cities we work in can trace the DNA of our work back to Wayne's work. He was also the most generous, inclusive supporter of scholars, activists and policy folk."

-Jane Battersby, Associate Professor, African Centre for Cities, University of Cape Town

"He was a longstanding inspiration in international food studies and food policy. A real innovator and creative thinker, [who combined these qualities] with a deep understanding of real politics and getting things done. He was also a lovely person and human being, a pleasure to be with and a very engaging and always inquisitive conversationalist."

- Terry Marsden, Professor of Environmental Policy and Planning, Director of PLACE, Cardiff University 
Wayne adopted a deeply pragmatic approach, recognizing the need for a range of political views on any committee seeking to effect policy change. He posited diverse political representation as a conscious strategy. Referring to the 2010 advocacy efforts around the Toronto Food Strategy, he said, "Part of that work is that every committee had a right, left, and centre person on it." He further explained, "I always made the distinction that we're not non-political, we're nonpartisan... Our position is for food." Moreover, Wayne sought to diversify representation on the Toronto Food Policy Council to ensure it was "bulletproof... that is, so beyond reproach as to be immune to Conservative attack." This meant establishing a collective mix of credentials, social identities, and lived experiences, even though he recognized the risk of inadvertently reinforcing an elitist element through this strategy.

Another related aspect of Wayne's pragmatic approach lay in framing food as a potential economic contributor, not only in terms of revenue generation and community economic development, but also as a mode of job creation. On this theme, he joked about his time at the Toronto Food Policy Council: "I wore a suit and tie every day to work, because I was promoting food as having job creation possibilities. What's the uniform of people who create jobs? A suit and tie!"' Wayne chuckled, "Some guy said: 'Hey, it's casual Friday,' and I said: 'This is casual.'... If you are proposing something economic, it's just a fact, you've got to wear a suit and tie."

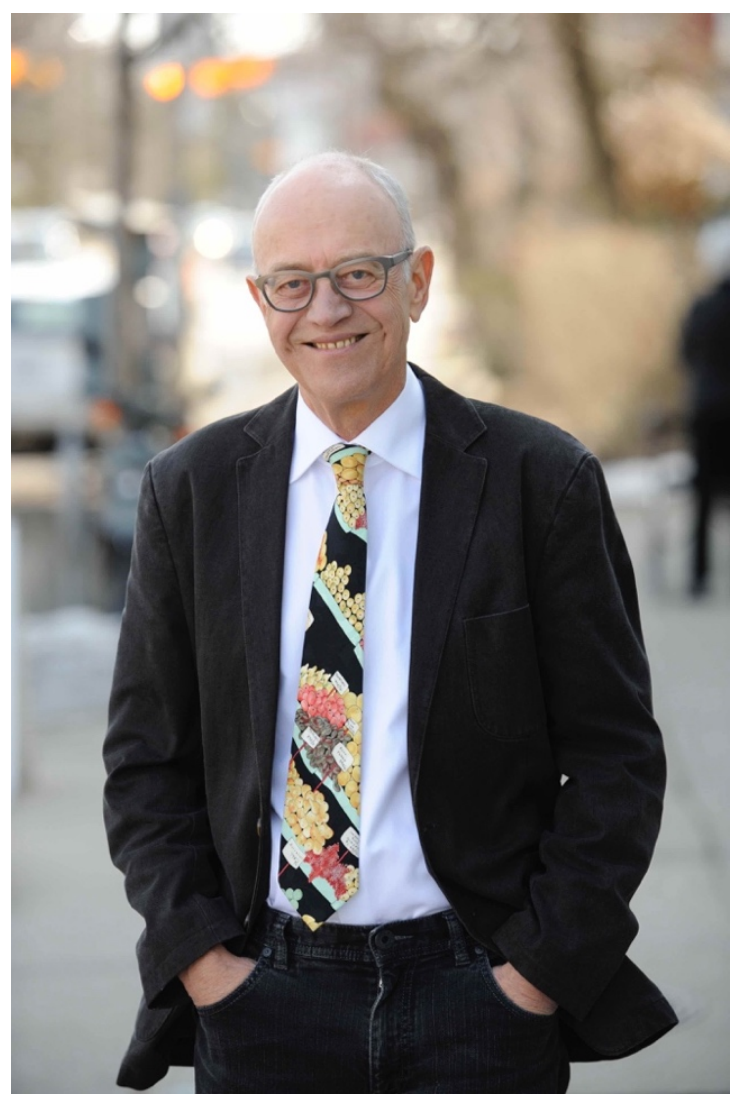

Photo credit: Michelle Quance 


\section{Form alliances with academics and other champions}

Academic scholarship held a special place in Wayne's heart and mind. While he spent most of his life either working for or in service of civil society organizations, Wayne conducted research, wrote scholarly papers, presented at academic conferences, and taught at post-secondary institutions throughout. He observed that universities had changed significantly over time: "The idea of the university as an ivory tower has ceased to be a dominant reality. Now the university has become a centre of the new knowledge economy and part of the overall functioning of society."

Throughout our interviews, Wayne spoke of scholars situated within the academy as playing an essential role in food movements - notably, through their contributions to food systems thinking. He saw academics as bringing additional resources to food movement work, including funding, access to space, applied student research capacity, and more. "These academics are opening the door to connect food and knowledge and push [new and diverse] ideas of food as part of systems thinking." In this way, Wayne suggested that post-secondary institutions "are not just about [developing] food studies, but also about using the university as a lever that can work with food to develop a transformative agenda." He saw an important role for academics to present new research to the broader public and frame food studies as a path to employment. Wayne noted that key academics created space in scholarly debates for discussions about "food as a topic in its own right... more than just food safety and nutrition." He stated that this advanced approach to food systems thinking has "led to qualitatively different conversations, that is, beyond nutritionism."

Wayne characterized some individuals as academic entrepreneurs - people who took risks within their professional positions to support civil society organizations and practitioners in their work and in the co-creation of knowledge. In doing so, they made universities more accessible places for public discussion and debate. He recognized that such people "go beyond academia, by using their academic positions to move in a broader sense." He described individuals who started coalitions and networks, who challenged conventional thinking by exposing the limitations of academia, and who offered paths forward for food systems thinking. These included scholars who helped build Food Secure Canada into a national food movement network, as well as students and professors who helped to develop university connections that helped legitimize the Toronto Food Policy Council. Wayne also spoke about the Food for Talk discussion series in the early $2000 \mathrm{~s}$ - a collaboration among Ryerson University, York University, and the University of Toronto. The series involved regular lectures and workshops that brought together members of the three university communities - as well as civil society actors and activists across a range of sectors - to engage with critical ideas about food systems. This series also increased international collaborations in food movements in Toronto and across Canada. Similarly, Wayne also noted how CAFS not only connects academics with each other but also pulls in activists, practitioners, and policy actors to participate in and share experiences. 
These examples emphasize the merits of what Wayne called "using universities as levers to make food a transformative agenda." Looking forward, he suggested that universities might serve a valuable role in encouraging and assisting cities to be vibrant and dynamic places and to accomplish many of their goals. For example, academics could take on "worthy projects" by figuring out what is holding government back from making progress on a given issue and contribute to the necessary knowledge and tools. Ultimately, Wayne felt that academics need to take this role much more seriously, using their power to support food systems change.

Wayne also made alliances with food systems champions outside of academia - those working on the ground in grassroots struggles, and with political actors with whom he shared core values. Notably, he worked closely with Debbie Field, the Executive Director of FoodShare Toronto from 1992 to 2017, and later Coordinator of the Coalition for Healthy School Food (Canada). Wayne paraphrased Debbie's idea that "we're building inch by inch now, and we'll be building inch by inch until we die." He went on to joke, "I barely went to the bathroom without consulting Debbie Field... I was checking in with her, and she with me, every day." Moreover, Debbie took on tough political issues on Wayne's behalf, protecting his role as a civil servant and advancing the goals of the Toronto Food Policy Council. "She wasn't an idealogue... She was so unbelievably respected." Similarly, Wayne worked closely with Brian Gilvesy, who he called "one of Canada's most-recognized farm innovators, as well as one of the country's bestknown leaders of the food movement" (Roberts 2015, p. 20). Together, they documented and shared Brian's perspectives and approaches to food system sustainability. Wayne eventually published two articles in Canadian Food Studies/La Revue canadienne des études sur l'alimentation, presenting this research to a larger audience (Roberts 2014c; 2015).

\section{Conclusion}

This interview has highlighted a range of thoughts of food systems thinker, public intellectual, and "actionist" Wayne Roberts - a unique individual who drew on intellect, humour, and vision to effect change. Wayne often cited Canadian politician Tommy Douglas' call to "dream no small dreams." It is an imperative Wayne himself embodied. During one of our conversations, he laughed and said, "If you want to move and shake, you have got to be a mover and a shaker!" Clearly, Wayne moved and shook - in Toronto and across the globe. While this article highlights some of his key allies, Wayne recognized many other people he worked with and learned from. He was far from a lone hero. He forged close personal bonds from his professional affiliationsfriends he viewed as "co-conspirators" in the fight to build a more just and sustainable world. In his celebration of life, many expressed that meeting Wayne for the first time was like reuniting with a long-lost friend you never knew you had. 
The impact of this human-centered intellectual - the legacy of his academic and activist work, the seeding of food policy councils, the tipping towards food systems thinking, and the rich personal and professional connections - cannot be understated.

\author{
"He was a true public intellectual, a professor whose class was \\ everywhere he could speak or write. He made food studies part of popular \\ discourse. I will remember his laughter and smile. Farewell brother!" \\ -Mustafa Koç, Professor, Sociology, Ryerson University
}

Ethics statement: This research received ethics approval from Research Ethics Boards at Lakehead University and Carleton University. In addition, Wayne Roberts consented to sharing this interview publicly, and the transcript has been reviewed by his wife and colleague, Lori Stahlbrand.

Acknowledgements: This interview was made possible through the Participatory Food Governance project and the team that contributed to developing the research project (including the key themes and interview guide). Specifically, we would like to thank Peter Andrée, Amanda Wilson, Moe Garahan, Phil Mount, Larry McDermont, Monika Korzun, Trudi Zundel, Kirsti Tasala, Gisèle Yasmeen, and Nathalie McSween. We also thank Alison Blay-Palmer and Lori Stahlbrand for reviewing the manuscript and providing helpful feedback, and David Szanto for his expert editorial advice. We are grateful for financial support from the Social Science and Humanities Research Council of Canada (SSHRC).

\title{
References
}

CBC News. (2021, January 22). Community remembers writer, food policy analyst, activist Wayne Roberts. https:/www.cbc.ca/player/play/1847436355809

Harris, J. (2021, January 29). Remembering food policy writer Wayne Roberts: A radical happyist. Corporate Knights. https://www.corporateknights.com/magazines/2020-best-50issue/remembering-food-policy-writer-wayne-roberts-a-radical-happyist-16119180/

Gladwell, M. (2000). The Tipping Point: How little things can make a big difference. Little Brown.

Koç, M., MacRae, R., Desjardins, E., \& Roberts, W. (2008). Getting Civil About Food: The interactions between civil society and the state to advance sustainable food systems in Canada. Journal of Hunger \& Environmental Nutrition, 3(2-3), 122-144. 
Pohl, C., Truffer, B., \& Hadorn, G.H. (2017). Addressing wicked problems through transdisciplinary research. In R. Frodeman (Ed.), The Oxford handbook of interdisciplinarity, (pp. 319-31). Oxford University Press.

Roberts, W. (2020, March 26). Four ways COVID-19 will change food systems and food security. Medium. https://medium.com/wayne-roberts/four-ways-covid-19-will-changefood-systems-and-food-security-f2ff04de555

Roberts, W. (2016). Food policy encounters of a third kind: how the Toronto food policy council socializes for sustain-ability. In A. Blay-Palmer (Ed.). Imagining sustainable food systems: theory and practice (pp. 173-200). Routledge.

Roberts, W. (2015). Life of Bryan: Working the magic of sustainable food's sweet spot, part 2. Canadian Food Studies/La Revue canadienne des études sur l'alimentation, 2(1), 9-15.

Roberts, W. (2014a). The no-nonsense guide to world food. New Internationalist Publications Ltd.

Roberts, W. (2014b). Food for city building: A field guide for planners, actionists \& entrepreneurs. BookBaby.

Roberts, W. (2014c). Life of Bryan: Working the magic of sustainable food's sweet spot. Canadian Food Studies/La Revue canadienne des études sur l'alimentation, 1(1), 20-26.

Roberts, W. (2009). How Toronto found its food groove. In: C. Palassio \& A.S. Wilcox. The edible city. Toronto's food from farm to fork (pp. 292-299). Coach House Books.

Roberts, W. (1994). Don't call me servant: Government work and unions in Ontario, 19111984. Ontario Public Service Employees Union.

Roberts, W. (2001). The way to a city's heart is through its stomach. Toronto Food Policy Council.

Roberts, W., MacRae, R., \& Stahlbrand, L. (1999). Real food for a change: Bringing nature, health, joy and justice to the table. Random House Canada.

Roberts, W., \& Brandum, S. (1995). Get a life! How to make a good buck, dance around the dinosaurs and save the world while you're at it. Get a Life Publishing.

Roberts, W., \& Ehring, G. (1993). Giving away a miracle: Lost dreams, broken promises and the Ontario NDP. Mosaic Press.

Sustain Ontario. (2021, January 23). Rest in power, Wayne Roberts. https://sustainontario.com/2021/01/23/rest-in-power-wayne-roberts/

Wikipedia. (2021, February 1) Wayne Roberts (activist). https://en.wikipedia.org/wiki/Wayne_Roberts_(activist)

Winne, M. (2021, January 24). The no-nonsense guide to joy: Wayne Roberts - 1944 to 2021. https://www.markwinne.com/the-no-nonsense-guide-to-joy-wayne-roberts-1944-to-2021/ 